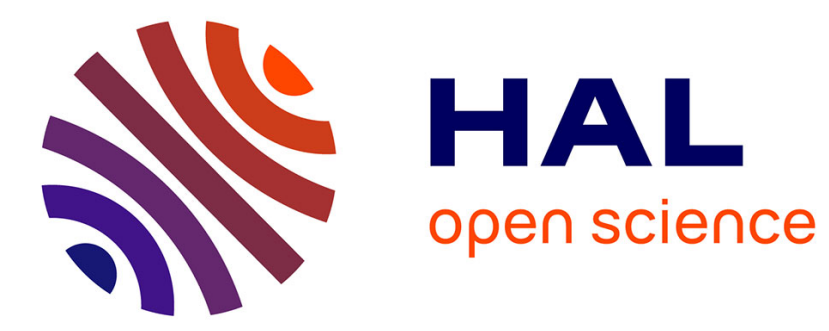

\title{
Towards enhancing business process modeling formalisms of EKD with consistency consideration
}

\author{
Afef Awadid, Selmin Nurcan
}

\section{To cite this version:}

Afef Awadid, Selmin Nurcan. Towards enhancing business process modeling formalisms of EKD with consistency consideration. The tenth IEEE International Conference on Research Challenges in Information Science (RCIS), Jun 2016, Grenoble, France. pp.1 - 12, 10.1109/RCIS.2016.7549306 . hal-01513002

\section{HAL Id: hal-01513002 \\ https://hal.science/hal-01513002}

Submitted on 24 Apr 2017

HAL is a multi-disciplinary open access archive for the deposit and dissemination of scientific research documents, whether they are published or not. The documents may come from teaching and research institutions in France or abroad, or from public or private research centers.
L'archive ouverte pluridisciplinaire HAL, est destinée au dépôt et à la diffusion de documents scientifiques de niveau recherche, publiés ou non, émanant des établissements d'enseignement et de recherche français ou étrangers, des laboratoires publics ou privés. 


\title{
Towards Enhancing Business Process Modeling Formalisms of EKD with Consistency Consideration
}

\author{
Afef Awadid, Selmin Nurcan \\ University of Paris 1 Pantheon-Sorbonne \\ Centre de Recherche en Informatique (CRI) \\ Paris, France \\ nurcan@univ-paris1.fr, afef.awadid@malix.univ-paris1.fr
}

\begin{abstract}
The Enterprise Knowledge Development (EKD) method promotes a holistic approach in Enterprise Modeling and advocates that a single modeling perspective (product, activity or role) is not sufficient for describing business processes. Instead, it offers a set of modeling formalisms, namely actor-role, roleactivity, and business objects formalisms, in order to capture the knowledge on enterprise processes view from different perspectives. On the one hand, this strengthens modeling complex business processes, but on the other hand this sets the requirement for dealing with the consistency among those models describing the same business process according to different perspectives. The systematic literature review we have conducted showed, among its findings, that there is no modeling tool supporting all these formalisms, and hence no way was proposed to handle their consistency. In multi-perspective modeling, the quality of the created models and their capability to be involved in the "design by reuse" depend strongly on the consistency among them. This paper aims to enhance the syntactic and semantic quality of EKD business process models by proposing a set of consistency rules controlling their dependencies. As the definition of semantic consistency rules is far from obvious, we have modeled and investigated a plethora of business processes from different domains. Our proposal is then supported by a tool in order to promote an automated consistency handling and hence to save the time and efforts of process modelers.
\end{abstract}

Keywords-EKD modeling formalisms; business process models; consistency rules; implementation; modeling tool

\section{INTRODUCTION}

Business processes are usually regarded as the key building blocks for a successful enterprise. Thereby, to further strengthen its competitive position, an enterprise has to continuously improve its business processes. This special attention granted to the business environment has given rise, among others, to the enterprise modeling topics, which not only facilitates the comprehension of business environment, but also is recognized as a valuable activity for the development of information systems [1], [2].

A method dedicated to business process modeling may cover various perspectives. Five perspectives have been proposed in [3] and have been extended with a sixth one (intentional) in [4]. The functional perspective highlights the activities to be performed in a business process. The process perspective characterizes the conditions to execute a process. The organization perspective reflects the organizational structure and actors involved in the business process. The information perspective includes data handled by business processes. The operation perspective describes elementary operations performed by resources and applications. Finally, the intentional perspective represents goals that the enterprise implements in its business processes. A modelling approach does not necessarily offer concepts to cover the six perspectives. Without a minimum set of perspectives, the resulting diagrams will have some deficiencies to highlight all essential characteristics of business processes.

Among enterprise modeling methods, we can find the Enterprise Knowledge Development (EKD) [5], [6], which advocates a design rationale driven approach to business process modeling. Also, instead of relying on a single modeling perspective (product, activity or role), EKD allows a multiperspective modeling of a business processes by viewing each of them as a composite of three key enterprise components: (a) the roles that are played by enterprise actors in order to reach the process goals (organizational perspective); (b) the activities involved in each role (functional and process perspective); (c) the objects that are involved together with their evolution from creation to extinction (informational perspective). This multiperspective modeling of a business process is revealed through the set of modeling formalisms EKD offers, namely Actor-Role (AR), Role-Activity (RA) and Business Objects (BO) formalisms. In AR formalism, the emphasis is on a high-level view of the association between actors and the different responsibilities (called roles) that they hold in different processes. In RA formalism, the emphasis is on a detailed view of the activities in which a role (of a given actor) is involved. Whereas, the BO formalism depicts resources (physical or informational) that are required by one or more activities being performed by the role.

Accordingly, these formalisms enable more exhaustive modeling of business processes since they seem to be sufficient for their understanding [7] as well as they reduce the complexity of a single model [8]. However, they give rise to consistency issue since they focus on the same business process [9]. In this context, our systematic literature review on the consistency among business process models showed among its findings that there is no modeling tool supporting all these formalisms, and hence no way was proposed to handle their consistency. To fill this gap, our work intends (i) to enhance the consistency among models/diagrams describing the same business process according to various perspectives promoted by EKD, (ii) to improve the quality of the produced models by proposing a set of consistency rules constraining their dependencies, and (iii) to strengthen the defined rules by a tool in order to allow an automated consistency handling.

The remainder of this paper is organized as follows. Section 2 outlines the modeling formalisms of EKD and their 
requirements for consistency by explicitly defining a set of syntactic consistency rules. Section 3 is dedicated to model and investigate a plethora of business processes with the aim of defining semantic consistency rules. We present an overview on the tool supporting the automation of the consistency rules in section 4. We summarize the related work in section 5. Section 6 is devoted to highlight the main lessons learned from our present work. We conclude our paper and discuss future directions in section 7 .

\section{BUSINESS PROCESS MODELING FORMALISMS OF EKD AND REQUIREMENTS FOR CONSISTENCY}

This section serves to briefly introduce the business process modeling formalisms of the EKD method and their metamodels as well as to emphasize their requirements for consistency by explicitly defining a set of consistency rules controlling their dependencies. The metamodels to which we refer in this section were originally presented in [5].

\section{A. Business process modeling formalisms of EKD}

The modeling formalisms offered by the EKD method in order to depict business processes in AR, RA and BO diagrams are briefly presented below.

\section{1) Actor-role modeling formalism}

An important point to note here is the distinction between the "actor", i.e. the definition of similar physical enterprise entities (customer, business unit manager, financial director), and the "role" which defines the responsibility assigned to an actor within a business process (loan request validator). The AR modeling formalism can be used to obtain a "first-cut" view of the organizational aspects [10] through depicting the enterprise actors and the roles that they fulfill in a business process in order to meet their responsibilities, known as operational goals. The roles are dependent on each other (it is either authorization, coordination, goal or resource dependency. In this formalism, the emphasis is put on the organizational perspective, which focuses on by whom and under the responsibilities of whom activities are performed. The concepts of actor-role meta-model are shown in Fig. 1.

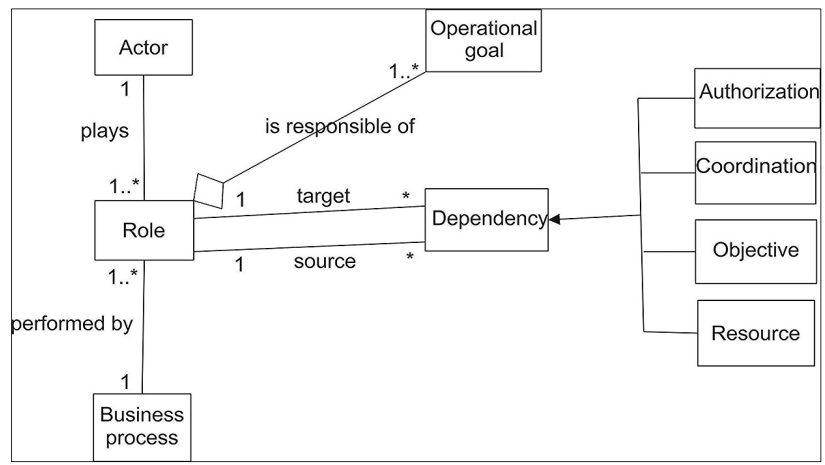

Fig. 1. Actor-role metamodel

\section{2) Role-activity modeling formalism}

This formalism is concerned with the operationalization of an actor's role in a business process by explicitly describing the activities incumbent upon it. It also depicts the interactions between the different roles involved in a business process in order to collectively achieve its goal. As to this formalism, the perspectives captured are the functional one referring to the activities performed during the process [9] and the process one, which focuses on when activities are performed and under what constraints. Fig. 2 shows corresponding metamodel.

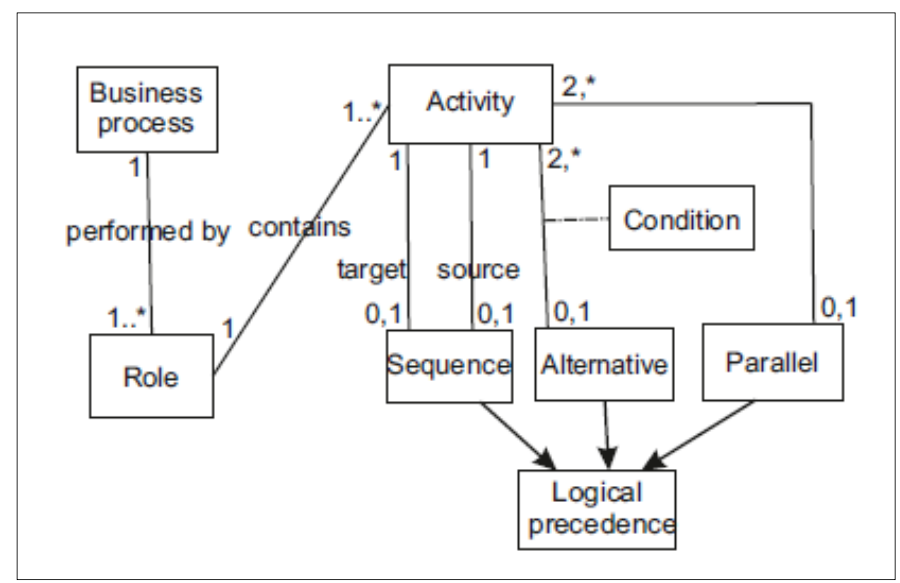

Fig. 2. Role-activity metamodel

\section{3) Business objects modeling formalism}

This formalism focuses on completing the knowledge accumulated from the two other formalisms by describing the physical and informational elements of an enterprise that are required for its functioning as well as their interrelations. The added knowledge is particularly about defining information systems that support business processes. Hence, this formalism highlights the informational perspective that depicts the business objects handled by a process, their structures and the links between them [11], [12]. The Business Objects Model (BOM) contains a structural part outlined through a class diagram, and a dynamic part allowing describing business objects lifecycles according to activities carried out within business processes. The concepts of objects metamodel are shown in Fig. 3.

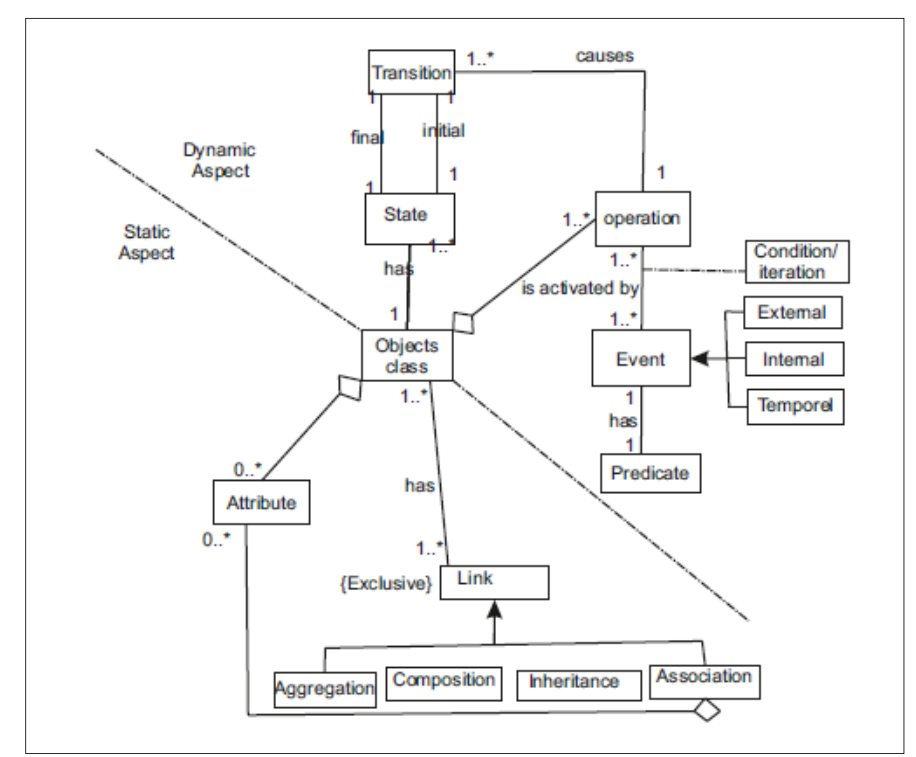

Fig. 3. Business objects metamodel 


\section{B. Requirements for consistency}

To promote a better understanding of business processes, the modeling formalisms of EKD, outlined in the above section A, allow depicting a business process from various perspectives (organizational, functional and process, informational). This leads to the existence of semantic relationships between the concepts of the three metamodels as evinced in Fig. 4.

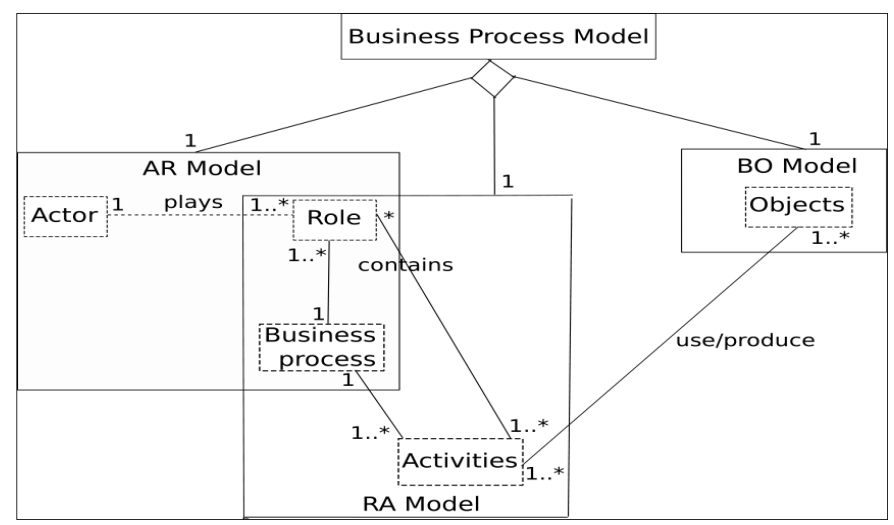

Fig. 4. Business process metamodel

Hence, it seems obvious that these formalisms are needed for getting a complete and thorough depiction of a business process. However, they also highlight the need for consistency among the various representations of the same business process.

1) Why the consistency among EKD formalisms is vital?

The consistency among EKD formalisms (namely AR, RA and $\mathrm{BO}$ diagrams) is viewed as vital. This is due to several reasons such as:

- The perspectives captured by these formalisms are complementary and then dependent on each other. They are somehow related not only on syntactic but also on a semantic basis. Thereby, dependencies between them should not be violated.

- The consistency is a key prerequisite of efficient and successful application of these formalisms.

- It is unavoidable for the utility of multi-perspective modeling approaches regardless the application domain [13].

- It is an important aspect on which depends the quality of the created models and, hence their capability to be involved in the "design by reuse" [14-17].

2) How to define consistency rules for EKD formalisms?

Before describing the way in which we have defined the kind of consistency rules, each of them needs to be specified.

a) Syntactic consistency rules: They refer to consistency rules of syntactic nature, which intend to guarantee that a model conforms to its abstract syntax (specified by its metamodel) [18]. This kind of rules exists, only if modeling concepts are part of the several perspectives they capture. It can be, then, deduced "by looking at the overlapping areas of the respective metamodels or by identifying shared concepts of a given common metamodel" [13]. Thereby, the metamodel outlined in Fig. 4 served us well in detecting syntactic consistency rules by focusing on the common parts between the three metamodels, which refer to the associations among their concepts. The detected rules are as follows:

- R-Syn-0: The Actor-Role Model (ARM), the RoleActivity Model (RAM) and the Business Objects Model (BOM) have to depict the knowledge about the same business process.

- R-Syn-1: Roles in an ARM and those in the corresponding RAM have to be the same.

- R-Syn-2: Each activity in a RAM should belong to one role in the corresponding ARM and, hence it should belong at least to one operational goal, in such way that no superfluous activity can be found in the RAM.

- R-Syn-3: Each business object in the BOM has to be able to refer, at least to one activity in the RAM, as consumed or produced resource (physical or informational) in such way that no superfluous business object can be found in the BOM.

b) Semantic consistency rules: These rules aim to ensure that models behavior be semantically compatible [18] and, hence to describe and preserve the semantic dependencies amongst the elements of the diverse perspectives [19]. However, semantic consistency rules are not identified that easy. Instead, one needs to have in depth knowledge of the semantics of the various perspectives [13]. Therefore, how shall we proceed to reveal this challenge?

\section{TOWARDS IDENTIFYING SEMANTIC \\ CONSISTENCY RULES: MODELING AND INVESTIGATING} A PLETHORA OF BUSINESS PROCESSES

In this section, we first present an overview of the business processes we have modeled and investigated, with the aim of drawing conclusions regarding the semantic dependencies among the created models. Then, in the light of these conclusions, we explicitly define a set of semantic consistency rules for EKD formalisms. Last, we rely on one amongst the modeled business processes in order to perform a first validation of the relevance of the defined consistency rules.

\section{A. Modeling and investigating business processes}

In order to account for the diversity in the kind of business processes, we modeled 14 business processes referring to various domains such as the education, health and hostelry domains. For each modeled business process, the number 1 is given to the model, which is created first, the number 2 for the one that is created in a second step, and the number 3 for the third created model.

As business objects provide a natural way to model the enterprise [20], we started firstly creating the BOM (where the order is marked in bold in Table 1). However, after being modeled the five first processes, we noted that each time the BOM and the ARM seemed to be semantically independent. This observation led us to change the order in which models are created by starting with either the ARM or the RAM for five other processes namely business expenses reimbursement, preparation for a surgery, book lending, electricity supply application fulfillment and nomination and selection of Nobel Prize laureate processes. In so doing, we were able to deduce some semantic links from the created models such as some common semantically equivalent concepts. 
Hence, we realized that a particular attention must be paid to the order in which models are created, when investigating the business process models. Reason for which, we decided to model all them in a systematic manner by following respectively the orders (llll $\left.\begin{array}{lll}1 & 2 & 3\end{array}\right),\left(\begin{array}{lll}1 & 3 & 2\end{array}\right),\left(\begin{array}{lll}2 & 1 & 3\end{array}\right),\left(\begin{array}{lll}2 & 3 & 1\end{array}\right),\left(\begin{array}{lll}3 & 1 & 2\end{array}\right)$ and $\left(\begin{array}{ll}3 & 2\end{array}\right)$, when creating the EKD business process models (ARM, RAM and BOM). The number of common concepts refers to the sum between the numbers of concepts semantically equivalent and shared between models numbered 1 and 2 and of those semantically equivalent and shared between the models numbered 2 and 3. This sum is given for each order. The first author, under the supervision of the second, has built all diagrams. The way of summarizing the lessons learnt for understanding consistency issues and inter-dependencies among the models and their order of construction have been discussed through numerous brainstorming workshops involving the two authors.

The number of common concepts (last column) was determined first in order to fill the three other columns, respectively number of actors, number of activities and number of operational goals. The set of values shown in these three columns refers to the order in the model creation (among the six possible), which has led to the higher value of the number of common concepts. An overview of the modeled business processes is presented in Table 1 .

TABLE I. AN OVERVIEW OF THE MODELED BUSINESS PROCESSES

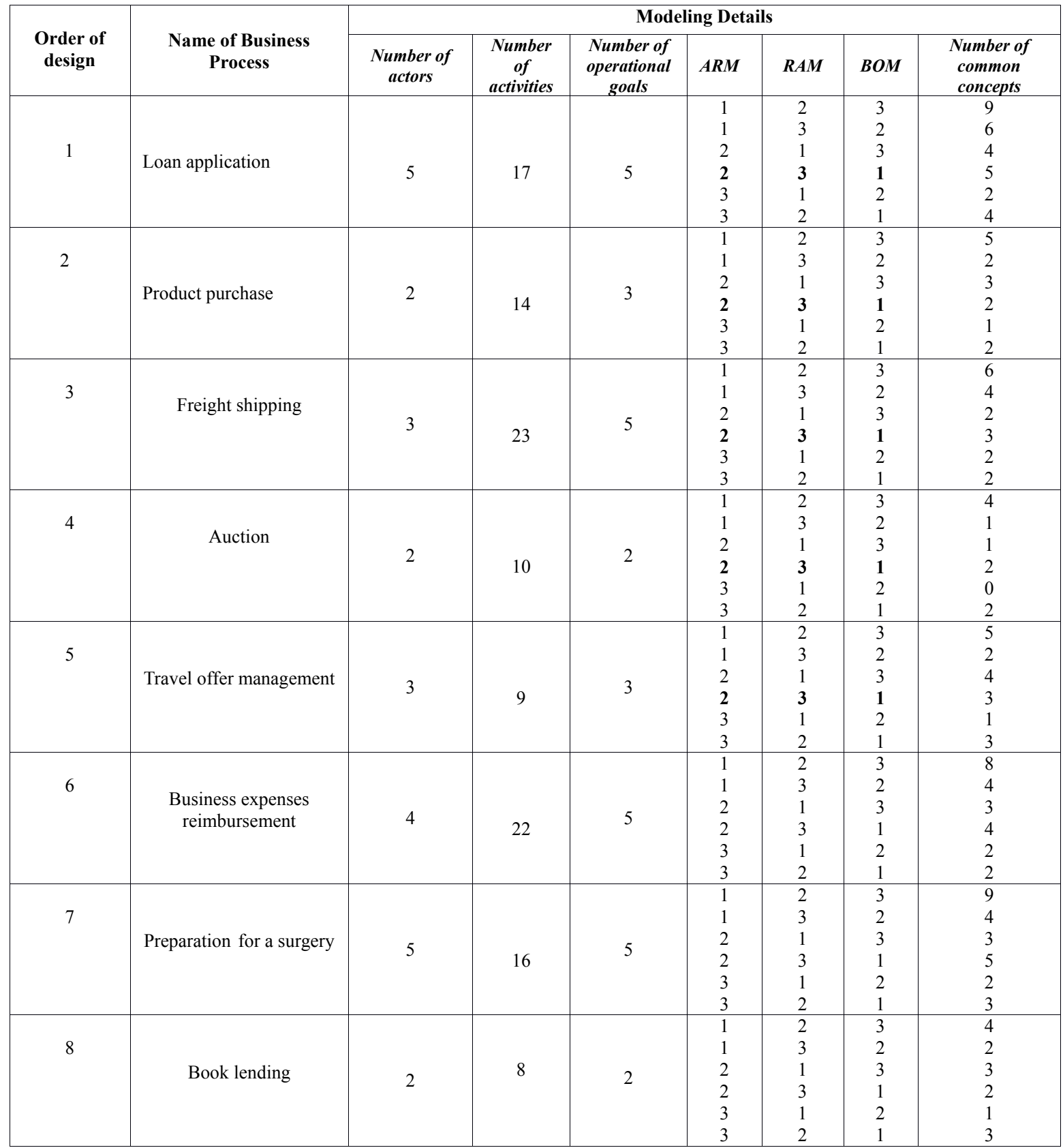




\begin{tabular}{|c|c|c|c|c|c|c|c|c|}
\hline 9 & $\begin{array}{l}\text { Electricity supply } \\
\text { application fulfilment }\end{array}$ & 4 & 25 & 8 & $\begin{array}{l}1 \\
1 \\
2 \\
2 \\
3 \\
3\end{array}$ & $\begin{array}{l}2 \\
3 \\
1 \\
3 \\
1 \\
2\end{array}$ & $\begin{array}{l}3 \\
2 \\
3 \\
1 \\
2 \\
1\end{array}$ & $\begin{array}{l}6 \\
4 \\
3 \\
4 \\
2 \\
3 \\
\end{array}$ \\
\hline 10 & $\begin{array}{c}\text { Nomination and } \\
\text { selection of Nobel prize } \\
\text { laureate }\end{array}$ & 3 & 17 & 3 & $\begin{array}{l}1 \\
1 \\
2 \\
2 \\
3 \\
3\end{array}$ & $\begin{array}{l}2 \\
3 \\
1 \\
3 \\
1 \\
2\end{array}$ & $\begin{array}{l}3 \\
2 \\
3 \\
1 \\
2 \\
1\end{array}$ & $\begin{array}{l}5 \\
4 \\
2 \\
3 \\
1 \\
4\end{array}$ \\
\hline 11 & $\begin{array}{l}\text { Incident management of } \\
\text { a software manufacturer }\end{array}$ & 5 & 15 & 5 & $\begin{array}{l}1 \\
1 \\
2 \\
2 \\
3 \\
3\end{array}$ & $\begin{array}{l}2 \\
3 \\
1 \\
3 \\
1 \\
2\end{array}$ & $\begin{array}{l}3 \\
2 \\
3 \\
1 \\
2 \\
1\end{array}$ & $\begin{array}{l}6 \\
5 \\
3 \\
5 \\
2 \\
2 \\
\end{array}$ \\
\hline 12 & $\begin{array}{l}\text { Project contractor } \\
\text { selection }\end{array}$ & 2 & 12 & 3 & $\begin{array}{l}1 \\
1 \\
2 \\
2 \\
3 \\
3\end{array}$ & $\begin{array}{l}2 \\
3 \\
1 \\
3 \\
1 \\
2\end{array}$ & $\begin{array}{l}3 \\
2 \\
3 \\
1 \\
2 \\
1\end{array}$ & $\begin{array}{l}4 \\
2 \\
2 \\
2 \\
1 \\
2\end{array}$ \\
\hline 13 & Leave application & 3 & 13 & 4 & $\begin{array}{l}1 \\
1 \\
2 \\
2 \\
3 \\
3\end{array}$ & $\begin{array}{l}2 \\
3 \\
1 \\
3 \\
1 \\
2 \\
\end{array}$ & $\begin{array}{l}3 \\
2 \\
3 \\
1 \\
2 \\
1 \\
\end{array}$ & $\begin{array}{l}5 \\
4 \\
2 \\
3 \\
2 \\
3 \\
\end{array}$ \\
\hline 14 & Cab booking & 3 & 16 & 4 & $\begin{array}{l}1 \\
1 \\
2 \\
2 \\
3 \\
3\end{array}$ & $\begin{array}{l}2 \\
3 \\
1 \\
3 \\
1 \\
2\end{array}$ & $\begin{array}{l}3 \\
2 \\
3 \\
1 \\
2 \\
1\end{array}$ & $\begin{array}{l}8 \\
4 \\
5 \\
4 \\
2 \\
5\end{array}$ \\
\hline
\end{tabular}

We show, here, the way in which we have determined the number of common concepts for the cab booking process, when the order in the model creation is respectively $\left(\begin{array}{lll}1 & 2 & 3\end{array}\right)$ and ( $\left.\begin{array}{lll}3 & 1 & 2\end{array}\right)$. By following the order $\left(\begin{array}{lll}1 & 2 & 3\end{array}\right)$, the produced models are illustrated through Fig. 5, Fig. 6 and Fig. 7.

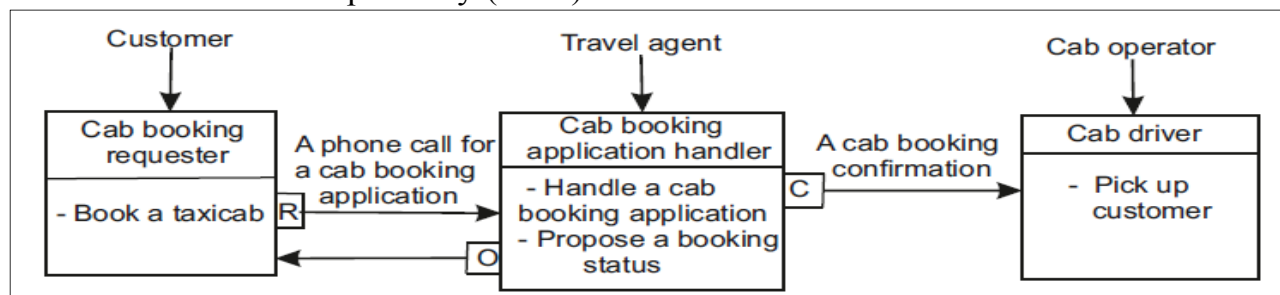

Fig. 5. ARM for the cab booking process 


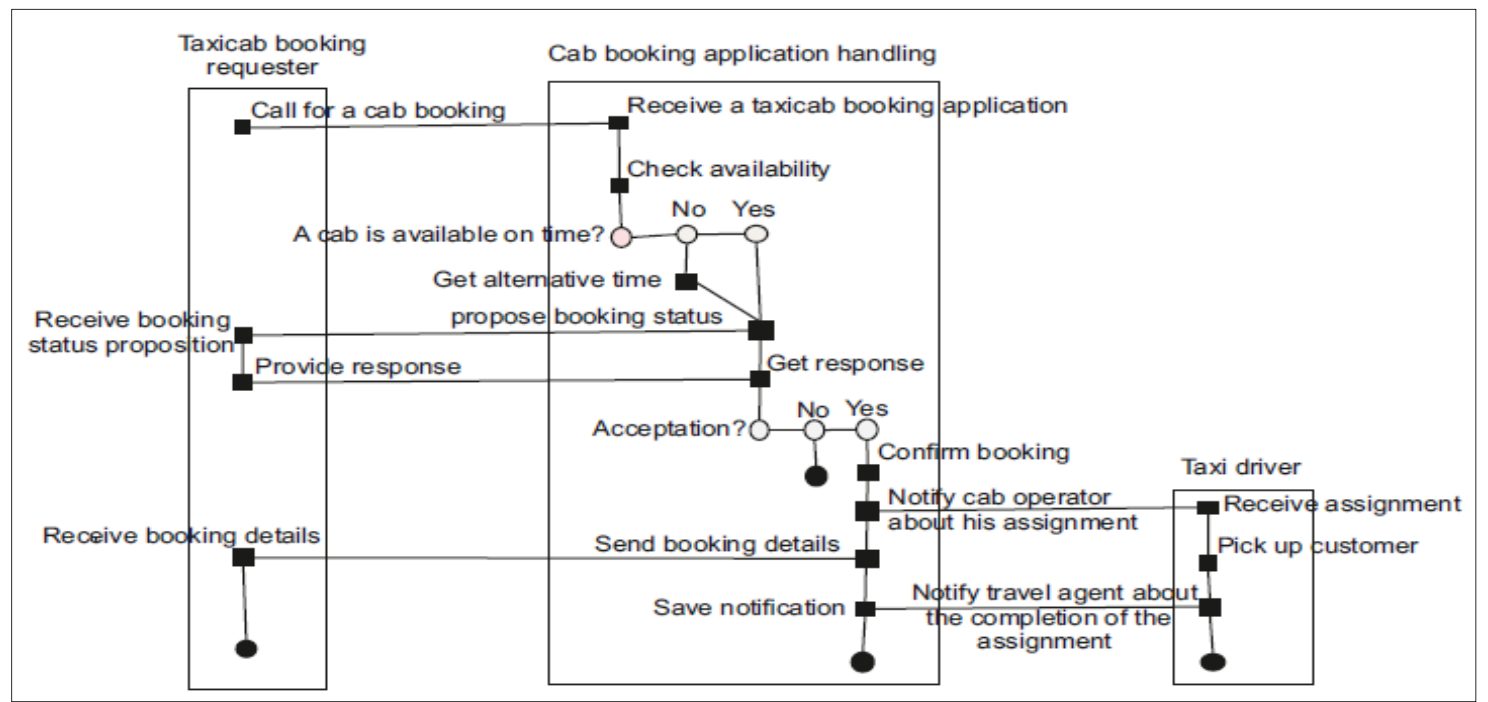

Fig. 6. RAM for the cab booking process

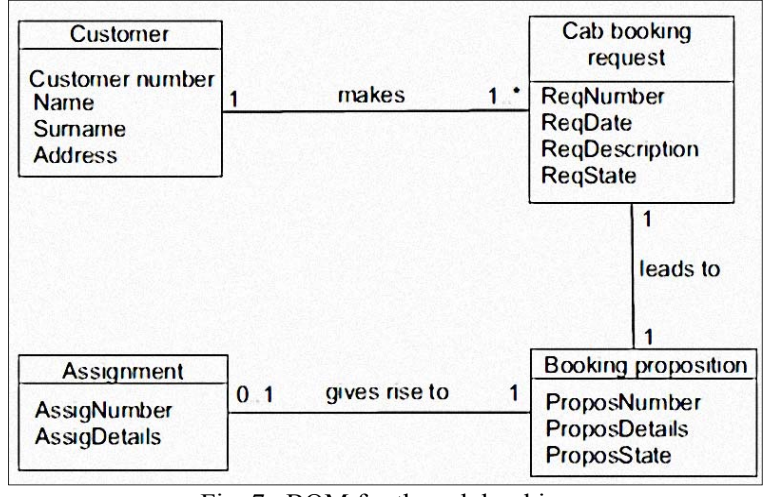

Fig. 7. BOM for the cab booking process

Table 2 and Table 3 show how we have determined the number of common concepts for the cab booking process for the order $\left(\begin{array}{lll}1 & 2 & 3\end{array}\right)$.

TABLE II. DETERMINATION OF THE NUMBER OF THE COMMON CONCEPTS SEMANTICALLY EQUIVALENT AND SHARED BETWEEN THE ARM AND THE RAM

\begin{tabular}{|c|c|c|c|}
\hline & $\begin{array}{c}\text { ARM } \\
\text { (numbered 1) }\end{array}$ & $\begin{array}{c}R A M \\
\text { (numbered 2) }\end{array}$ & $\begin{array}{c}\text { Number } \\
\text { of } \\
\text { concepts }\end{array}$ \\
\hline \multirow{5}{*}{$\begin{array}{l}\text { Concepts } \\
\text { semantically } \\
\text { Equivalent }\end{array}$} & $\begin{array}{c}\text { Cab booking } \\
\text { requester }\end{array}$ & $\begin{array}{c}\text { Taxicab booking } \\
\text { requester }\end{array}$ & \multirow{5}{*}{5} \\
\hline & $\begin{array}{l}\text { A phone call for a } \\
\text { cab booking } \\
\text { application }\end{array}$ & $\begin{array}{l}\text { Call for a cab } \\
\text { booking }\end{array}$ & \\
\hline & $\begin{array}{c}\text { Cab booking } \\
\text { application handler }\end{array}$ & $\begin{array}{c}\text { Cab booking } \\
\text { application } \\
\text { handling }\end{array}$ & \\
\hline & $\mathrm{Cab}$ driver & Taxi driver & \\
\hline & Pick up customer & Pick up customer & \\
\hline
\end{tabular}

TABLE III. DETERMINATION OF THE NUMBER OF THE COMMON CONCEPTS SEMANTICALLY EQUIVALENT AND SHARED BETWEEN THE RAM AND THE BOM

\begin{tabular}{|c|c|c|c|}
\hline & $\begin{array}{c}\text { RAM } \\
\text { (numbered 2) }\end{array}$ & $\begin{array}{c}\text { BOM } \\
\text { (numbered 3) }\end{array}$ & $\begin{array}{c}\text { Number of } \\
\text { concepts }\end{array}$ \\
\hline \multirow{4}{*}{$\begin{array}{c}\text { Concepts } \\
\text { semantically } \\
\text { equivalent }\end{array}$} & $\begin{array}{c}\text { Cab booking } \\
\text { application }\end{array}$ & $\begin{array}{c}\text { Taxicab booking } \\
\text { request }\end{array}$ & \multirow{2}{*}{} \\
\cline { 2 - 3 } & Booking status & Booking proposition & \multirow{2}{*}{4} \\
\cline { 2 - 3 } & Assignment & Assignment & \\
\cline { 2 - 3 } & Customer & Customer & \\
\hline
\end{tabular}

In this case, the number of common concepts equals $9(4+5)$. By following the order $\left(\begin{array}{lll}3 & 1 & 2\end{array}\right)$, the produced models are shown respectively in Fig. 8, Fig. 9 and Fig. 10. 


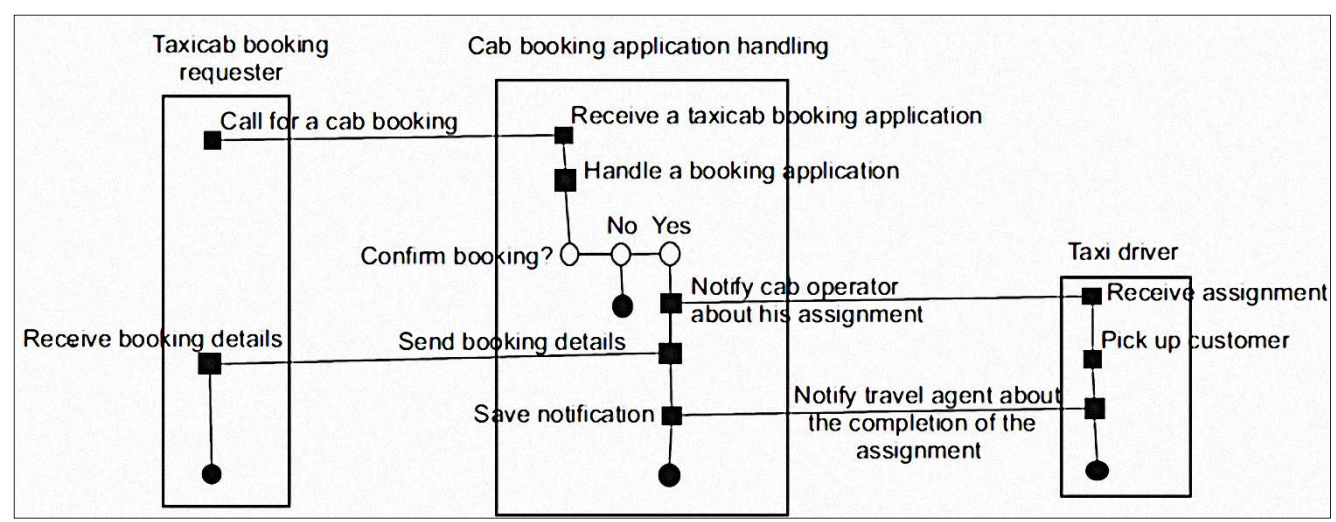

Fig. 8. RAM for the cab booking process

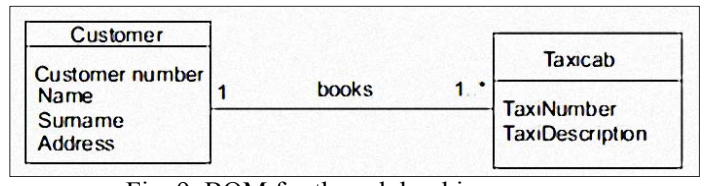

Fig. 9. BOM for the cab booking process

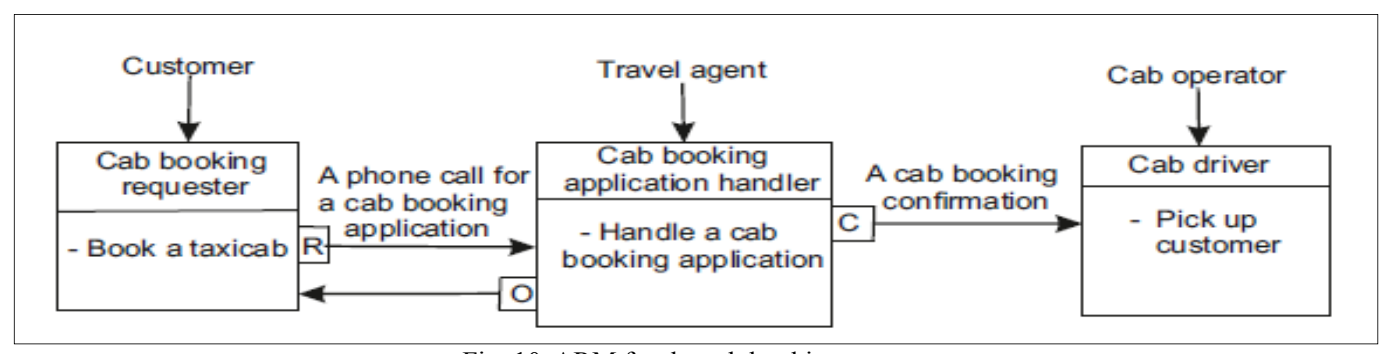

Fig. 10. ARM for the cab booking process

Table 4 and Table 5 show how we have determined the number of common concepts for the cab booking process for the order $\left(\begin{array}{lll}3 & 1 & 2\end{array}\right)$.

TABLE IV. DETERMINATION OF THE NUMBER OF THE COMMON CONCEPTS SEMANTICALLY EQUIVALENT AND SHARED BETWEEN THE RAM AND THE BOM

\begin{tabular}{|c|c|c|c|}
\hline & $\begin{array}{c}\text { RAM } \\
\text { (numbered 1) }\end{array}$ & $\begin{array}{c}\text { BOM } \\
\text { (numbered 2) }\end{array}$ & $\begin{array}{c}\text { Number of } \\
\text { concepts }\end{array}$ \\
\hline $\begin{array}{c}\text { Concepts } \\
\text { semantically } \\
\text { equivalent }\end{array}$ & Taxicab / taxi & Taxicab & \multirow{2}{*}{2} \\
\cline { 2 - 3 } & Customer & Customer & \\
\hline
\end{tabular}

TABLE V. DETERMINATION OF THE NUMBER OF THE COMMON CONCEPTS SEMANTICALLY EQUIVALENT AND SHARED BETWEEN THE BOM AND THE ARM

\begin{tabular}{|c|c|c|c|}
\hline & $\begin{array}{c}\text { BOM } \\
\text { (numbered 2) }\end{array}$ & $\begin{array}{c}\text { ARM } \\
\text { (numbered 3) }\end{array}$ & $\begin{array}{c}\text { Number of } \\
\text { concepts }\end{array}$ \\
\hline $\begin{array}{c}\text { Concepts } \\
\text { semantically } \\
\text { equivalent }\end{array}$ & Customer & Customer & 1 \\
\hline
\end{tabular}

The number of common concepts for this order equals 3.

As we mentioned earlier "operational goal" and "activity" are considered as key concepts in respectively AR and RA formalisms. Moreover, based on the modeling of the fourteen business processes, we noticed that, for each one amongst them, the number of all activities in the RAM is equal at least three times the number of operational goals in the corresponding ARM, as shown in Table 1. The RAM is then created in order to better refine the ARM by offering a more detailed view of how to operationalize the operational goals it contains. Accordingly, when moving towards a more detailed level which refers to focus on each role separately, it is reasonable that, on one side the number of activities carried out by each role in the RAM should be more than the number of operational goals entrusted to this role in the corresponding ARM, and on the other side, each operational goal has to be able to be translated at least into two activities. In this sense, the ARM embodies a form of high-level modeling, while the RAM depicts a form of mid-level modeling. The BOM epitomizes then, the low-level modeling, since it constitutes the central link between the business processes and the software applications that support them [21].

One way to understand the meaning of the relationship between the high-level modeling and the mid-level modeling in this case, lies in recognizing that each role in the ARM is induced to perform a sequence of activities in order to meet an operational goal it strives to satisfy. Hence, the first activity in this sequence refers semantically to the first step towards the achievement of a given operational goal. Whereas, the last activity in the sequence amounts semantically to the operational goal itself. For instance, for the process of electricity supply application fulfillment, where the role "service requester" is associated with "get connected to the electricity network" as operational goal in the ARM, the first activity entrusted to this role in the corresponding RAM is "submit electricity supply application form". In fact, submitting an electricity supply application form corresponds to the first step towards the connection to the electricity network. Furthermore, the last 
activity performed by this role is "Receive the notification of the application fulfillment" which is semantically equivalent to "get connected to the electricity network". Moreover, since business objects, defined as informational and physical resources, set the structure of the support systems and their behavior has an identifiable life-cycle, the actors (referring to a set of organizational entities) as well as the resources on which the fulfillment of one or more operational goals depends, in the ARM can be considered as business objects, and hence they should be included in the corresponding BOM. Besides, by following the order $\left(\begin{array}{lll}1 & 2 & 3\end{array}\right)$ (i.e. the ARM is created first, then the RAM and finally the BOM), we noticed that the greatest number of common concepts is gained in this case. This means that this order allows getting much more semantic links between the three models compared mainly with the order $\left(\begin{array}{lll}3 & 1\end{array}\right)$ where the created models seem to be somehow semantically independent (since the number of common concepts does not exceed 3 as visualized in Table 5).

A particular attention to this notion of order in the field of multi-view modeling is given in [22] by defining a relationships category called "process relationships" within a comprehensive survey of relationships in integrated multi-view modeling of cyber-physical systems. This category investigates three types of relationships: (1) precedence relationship, when a certain view (i.e. perspective in our case) has to exist before another view without sharing data; (2) dependency relationship, when a certain view has to exist before another view with the second one contains data defined in the first view; and (3) codependency relationship in case of circular shared data among views. Thus, taking into account this category on one side, and bearing in mind what we have already drawn as findings on the other side, we believe that the fact of considering the dependencies highlighted in Fig. 11, when creating multiperspective business process models using the EKD formalisms is of a major importance in the strengthening of their consistency. Note that DR refers to "Dependency Relationship".
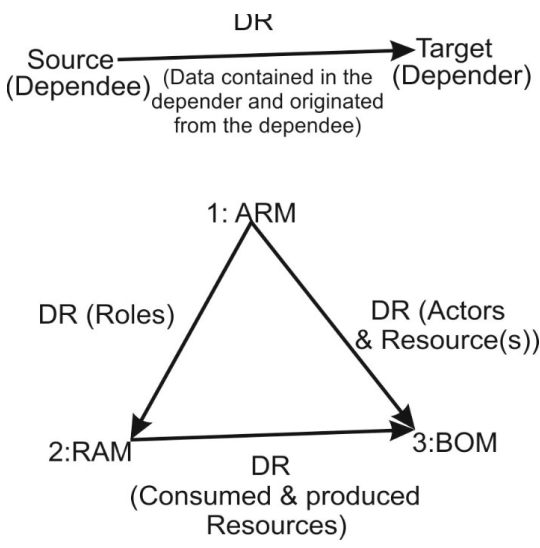

Fig. 11.Dependencies to be considered for a better consistency among EKD business process models.

According to this figure, the ARM is viewed as a dependee with regard to both RAM and BOM, since the two latter models contain data (roles, actors and resource(s)) originated from it. The finding highlighted through this figure, can be consolidated by a conclusion drawn in other works [23], [24], [25] given the strong analogy, which can be made with them. Indeed, these works deal with how to better manage change within EKDChange Management Method (EKD-CMM) [24] enterprise models namely Goals Model (GM), Business Process Models
(BPMs) and Information Systems Model (ISM). This notion of change management is also vital when dealing with consistency, since synchronization between perspectives in case a certain perspective undergoes change is unavoidable in order to guarantee a consistent model state [26], [27]. The analogy we have made with these works is exhibited in Table 6.

TABLE VI. AN ANALOGY WITH OTHER WORKS STRENGTHENING OUR FINDING

\begin{tabular}{|c|c|c|}
\hline $\begin{array}{c}\text { Work } \\
\text { Details }\end{array}$ & {$[23],[24],[25]$} & Our work \\
\hline $\begin{array}{l}\text { Models in } \\
\text { question }\end{array}$ & $\begin{array}{c}\text { EKD-CMM enterprise } \\
\text { models (GM, BPMs and } \\
\text { ISM) }\end{array}$ & $\begin{array}{c}\text { EKD business process } \\
\text { models (ARM, RAM and } \\
\text { BOM) }\end{array}$ \\
\hline $\begin{array}{c}\text { Abstraction } \\
\text { levels }\end{array}$ & $\begin{array}{c}\text { Intentional level (GM) } \\
\text { Organizational level } \\
\text { (BPMs) } \\
\text { Operational level (ISM) }\end{array}$ & $\begin{array}{l}\text { High-level modeling (ARM) } \\
\text { Mid-level modeling (RAM) } \\
\text { Low-level modeling (BOM) }\end{array}$ \\
\hline Conclusion & $\begin{array}{l}\text { Reasoning on enterprise } \\
\text { objectives, (i.e. } \\
\text { intentional level, which } \\
\text { corresponds to the high } \\
\text { abstraction level) makes } \\
\text { easier understanding of } \\
\text { problems. }\end{array}$ & $\begin{array}{l}\text { Reasoning on the high-level } \\
\text { model (i.e. considering the } \\
\text { ARM as a dependee with } \\
\text { regard to both RAM and } \\
\text { BOM) promotes a better } \\
\text { semantic consistency among } \\
\text { the created models. }\end{array}$ \\
\hline
\end{tabular}

\section{B. Defining semantic consistency rules}

In the light of the observations, we have drawn from the above section $A$, the initial semantic consistency rules that should constrain the dependencies between EKD business process models are listed below:

- R-Sem-0: When creating EKD business process models, the modeler has to follow the order $\left(\begin{array}{lll}1 & 2 & 3\end{array}\right)$ according to which, the ARM should be created first, then the RAM and finally the BOM.

- R-Sem-1: The first activity performed by the trigger of the process in the RAM has to refer semantically to the first step towards the achievement of his main operational goal in the corresponding ARM.

- R-Sem-2: The last activity in the RAM has to be semantically equivalent to one amongst the set of operational goals assigned to the corresponding role in the corresponding ARM. R-Sem-3: The number of activities carried out by each role in the RAM has to be greater than the number of operational goals entrusted to this role in the corresponding ARM.

- R-Sem-4: Each operational goal in the ARM has to be able to be translated at least into two activities in the corresponding RAM (i.e. it has not to be atomic).

- R-Sem-5: The actors in the ARM, have to be included as business objects in the corresponding BOM.

- R-Sem-6: Each resource (physical or informational) giving rise to a resource dependency in the ARM has to be included as a business object in the corresponding BOM.

- R-Sem-7: The ARM has to be viewed as a dependee with regard to both RAM and BOM. The compliance with this rule depends on the compliance with some other rues, in the sense that it can be satisfied only if the rules R-syn-1, R-sem-5 and R-sem- 6 have been satisfied. This rule is then unavoidable for a better 
semantic as well as syntactic consistency among the EKD business process models.

\section{A first validation of the defined consistency rules: an application case}

In order to validate the relevance as well as the strong need for the defined consistency rules, we have relied on the three complementary models of the business processes emphasized in section 3. Many inconsistencies mainly on the semantic level have been detected (mostly for the first six business processes) by referring to the proposed rules. We present, here, the case of the business expenses reimbursement process for the order (1 3 $2)$. The ARM, the RAM and the BOM associated with this process are illustrated respectively through Fig. 12, Fig. 13 and Fig. 14. Those three models have been produced in the early stages of the experimentation, before the elicitation of the semantic consistency rules presented in section III.B. We checked them against the eight semantic consistency rules in order to get a first validation of our semantic rules and their capacity to detect inconsistencies.

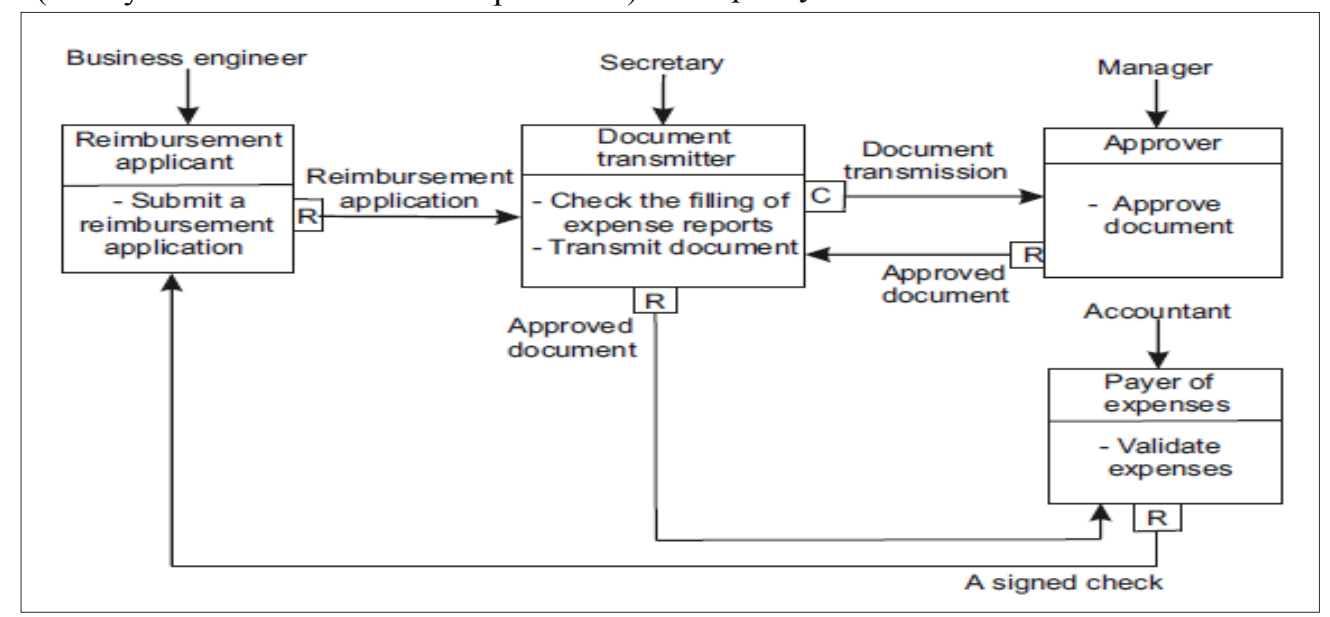

Fig. 12.ARM for the business expenses reimbursement process.

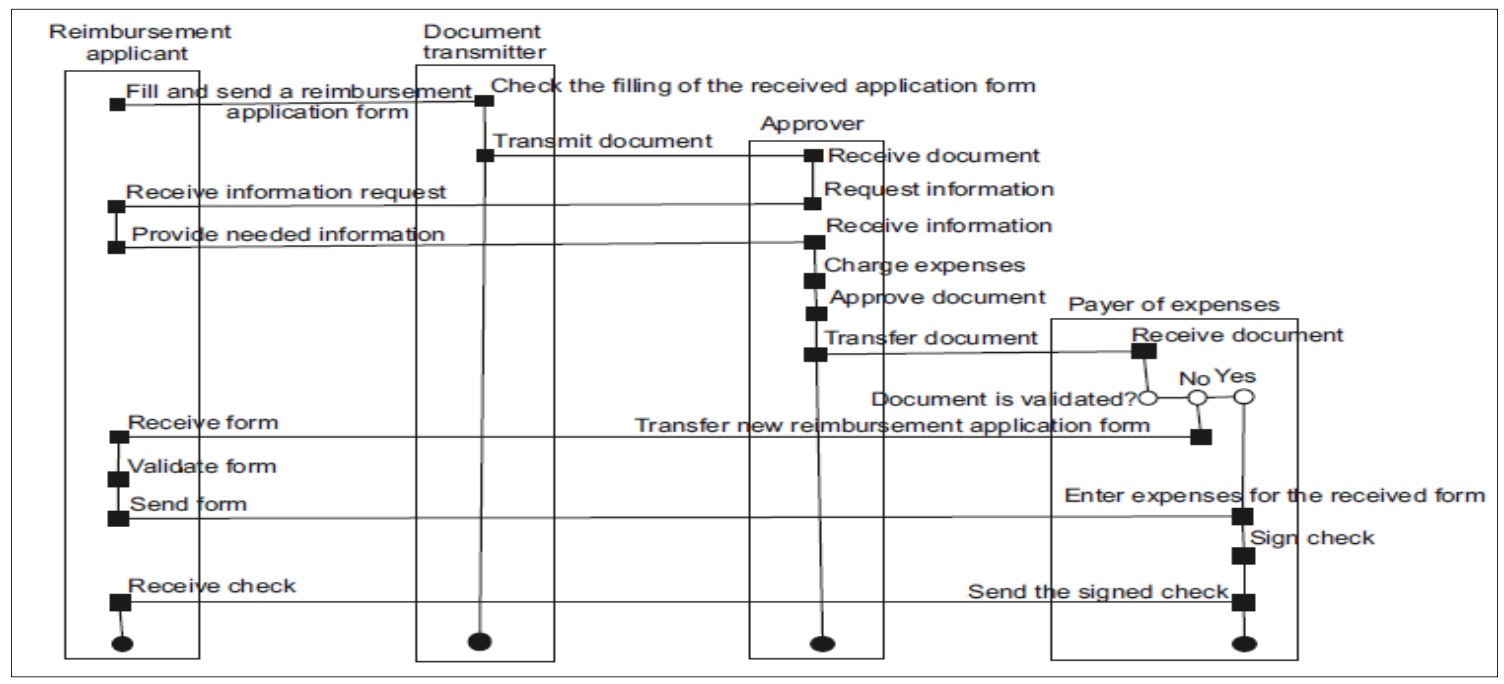

Fig. 13. RAM for the business expenses reimbursement process.

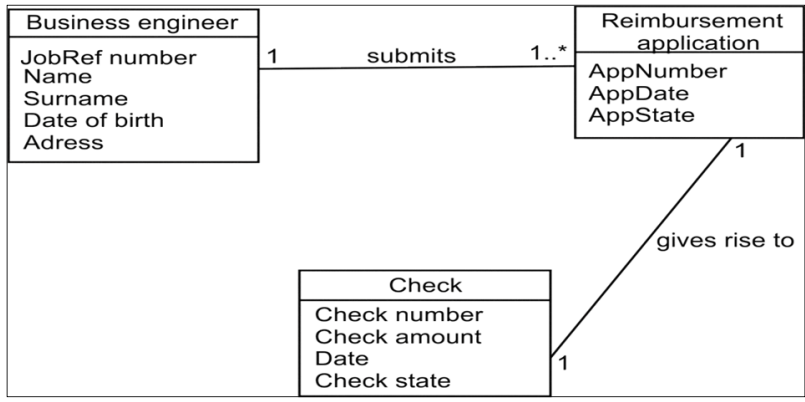

The validation of the relevance of the defined rules is evinced through several inconsistencies we have been able to detect thanks to the enforcement of these rules. The inconsistencies, which have been a posteriori detected, are summarized in Table 7.

Fig. 14. BOM for the business expenses reimbursement process. 
TABLE VII. DETECTING INCONSISTENCIES FORBUSINESS EXPENSES REIMBURSEMENT PROCESS MODELS

\begin{tabular}{|c|c|}
\hline $\begin{array}{c}\text { The violated } \\
\text { rule }\end{array}$ & The resulted inconsistencies \\
\hline R-sem-1 & $\begin{array}{l}\text { There is no semantical difference between the concept of } \\
\text { operational goal in the ARM and that of activity in the } \\
\text { corresponding RAM, since the operational goal" Submit } \\
\text { a reimbursement application" associated with the role } \\
\text { "Applicant" in the ARM can have the same meaning as } \\
\text { the activity "Fill a reimbursement application form" } \\
\text { performed by this role in the corresponding RAM, } \\
\text { which renders the building of the RAM meaningless. }\end{array}$ \\
\hline R-sem-2 & $\begin{array}{l}\text { The output of the process deduced from the last activity } \\
\text { in the RAM which is "Receive a signed check" is not } \\
\text { able to satisfy the operational goal of the trigger } \\
\text { ("Submit a reimbursement application") since the latter } \\
\text { is labeled as an activity and not as a goal ("get refunding } \\
\text { for the professional expenses"). This widens the } \\
\text { semantic gap between the ARM and the corresponding } \\
\text { RAM. }\end{array}$ \\
\hline $\begin{array}{l}\text { R-sem-3 } \\
\text { R-sem-4 }\end{array}$ & $\begin{array}{l}\text { The non-compliance with the refinement level affiliated } \\
\text { with each model (the ARM and the corresponding } \\
\text { RAM), since the role "Document transmitter" is } \\
\text { associated with two operational goals in the ARM, and is } \\
\text { concerned with performing two activities in the } \\
\text { corresponding RAM, which gives arise to an acute } \\
\text { confusion between these models. Reason for which, } \\
\text { many redundancies can be found in them. For instance, } \\
\text { the activities "Transmit document" and "Approve } \\
\text { document" associated respectively with the roles } \\
\text { "Document transmitter" and "Document approver" } \\
\text { appear at the same time as operational goals in the ARM } \\
\text { and as activities in the corresponding RAM. Moreover, } \\
\text { the activity "check the filling of the received application } \\
\text { form" in the RAM and which is associated to the } \\
\text { operational goal "check the filling of expenses reports" } \\
\text { in the corresponding ARM, has no feedback in the RAM }\end{array}$ \\
\hline
\end{tabular}

\begin{tabular}{|c|c|}
\hline R-sem-5 & $\begin{array}{c}\text { in order to inform the business engineer about the errors } \\
\text { he makes in case some errors have been detected during } \\
\text { the check process. }\end{array}$ \\
\hline $\begin{array}{c}\text { Business objects of a major importance have been } \\
\text { omitted from the BOM, such as the manager who } \\
\text { approves the document and the accountant who validates } \\
\text { the expenses. }\end{array}$ \\
\hline
\end{tabular}

The case study allowed us to perform a first validation of the relevance of the defined consistency rules. However, following this validation, we also observed that manual validation of the non-violation of rules is a tedious and time-consuming task for a modeler, mainly in case of quite complex business process models. Reason for which, implementing consistency rules towards a tool supporting an automated consistency handling is highly requested.

\section{A TOOL SUPPORTING AN AUTOMATED CONSISTENCY HANDLING}

To implement the business process modeling formalisms of EKD, we have relied upon the ADOxx platform, which is a meta-modeling-based development and configuration platform for implementing modeling tools [28]. The reasons for which we have chosen the platform ADOxx for implementing the business process modeling formalisms of EKD are the several advantages this platform provides mainly in terms of (1) scalability; it has extensive functionalities for implementing modeling languages and hence it offers many options for implementing arbitrary types of visual modeling languages [29], and (2) traceability and accountability: it offers a detailed changelog for any changes made to the models and evaluations [30]. A screenshot of the implementation of the actor-role formalism is shown in Fig. 15.

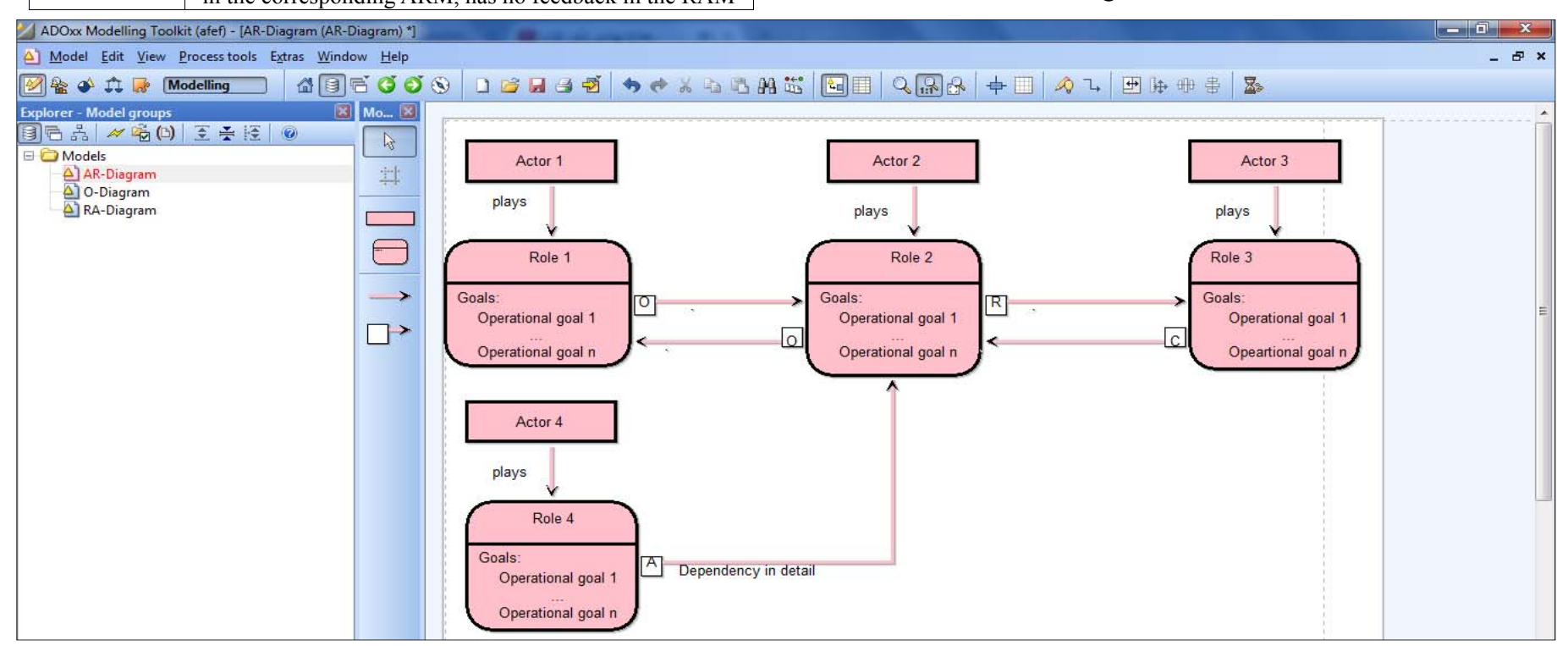

Fig. 15.A screenshot of the implementation of the actor-role modeling formalism

The syntactic consistency rules were taken into account during this implementation. In the sense that, they were implemented at meta-modeling level in order to allow modelers to automatically obtain business process models, which are syntactically consistent. In the near future, we intend to provide guidance to modelers, during the business process modeling process, to comply also with the defined semantic consistency rules. Moreover, we will perform the same experience in a larger scale, and ask to about 50 students of a master program to model the set of the 14 processes studied in this first experimentation. The aim of the new experimentation is threefold: (i) to validate the syntactic and semantic rules thanks to a significant number of modelers; (iii) to identify new semantic consistency rules thanks to independent modelers; and 
(iii) using various protocols for building the models, to investigate the impact of the modelers (each of them having their own point-of-view and scientific and professional background) on the produced artifacts (models) and their interconsistency.

\section{RELATED WORK}

When we have conducted a systematic literature review (SLR) on consistency among business process models which has been published in BPMDS'16 [33] and in which 41 papers were analyzed in depth. In this review, the emphasis has been set amongst others on the following preoccupations: (i) the existence or not of tools supporting the multi-perspective modeling methods, including EKD, and (ii) the issue of consistency among multi-perspective process models. With respect to the first preoccupation and where the concerned method is EKD, we have mainly found one work in literature [31], which briefly points to EKD lifecycle from conceptualization to a downloadable modeling tool ; the authors we have contacted informed us that the development was stopped. Regarding the second preoccupation, only one work [32] dealing with assessment of business process model of EKD was found. However, its focus was not on consistency of the business process model, but rather on its correctness with respect to set of requirements such as the absence of deadlocks and the soundness of model. Hence, despite the benefits that EKD method brings to enterprise in practice and in particular to business processes through offering different modeling formalisms for them, tools supporting the building and the evaluation of EKD business process model mainly with regard to consistency and compliance, are still missing. The SLR also revealed that (1) the majority of the existing approaches tackle the consistency checking (i.e. late/corrective consistency management) rather than preventing them (i.e. early/preventive consistency management), and (2) a special attention must be given to the consistency among multi-perspective BP models, where a notable lack of approaches has been noticed.

\section{LESSONS LEARNED}

This section deals with some of the lessons learned from this work, and which needed to be accounted for. These lessons lie in the following points:

- Once, we changed the order in which we created the EKD business process models during the modeling process, we were immediately able to define further semantic consistency rules of special interest (R-sem0 and R-sem-6). In this context, we are aware of the fact that redoing this modeling, by referring for each order to be followed when creating models to other independent modelers, is an appropriate way (1) for further validation of these rules and (2) for defining other potential rules.

- Following the modeling and investigation process of a plethora of business processes, we realized that the major asset of gaining a better consistency among the created models depends on whether or not the defined consistency rules have been enforced by the modeler, and hence whether or not they have been implemented in order to allow him/her to manage the inter-model consistency in an automated manner. Accordingly, a tool supporting an automated consistency handling is usually highly requested.

- One way to save the time and efforts of process modelers regarding the issue of inter-model consistency handling consists (i) in taking into account the syntactic consistency rules in the meta-modeling level as in a CASE tool (i.e. when implementing the modeling languages), and (ii) in guiding modelers to comply with the semantic consistency rules. This allows modelers to cope with the difficulty in understanding the poor feedback that the consistency check may produce, since it is usually expressed within the scope of the technique chosen (for instance, the formal technique used).

\section{CONCLUSION}

The EKD method advocates the multi-perspective modeling of complex business processes, as a valuable way for their better understanding. This is manifested through the set of modeling formalisms it offers namely actor-role, role-activity and business objects diagrams. Each of them captures a particular perspective on the same business process. Thereby, ensuring consistency among all perspectives is perceived as unavoidable. In this context, this paper proposed a set of syntactic and semantic consistency rules constraining the dependencies between these perspectives, with the aim of getting a better syntactic and semantic quality of the created models. The way in which we defined these rules and a first validation of them have been presented in this paper. We have supported our proposal by a tool in order to promote an automated consistency handling. This allows not only to save the time and efforts of process modelers, but also to promote the reusability of the created models. Currently, the tool supports the defined syntactic consistency rules, which have been implemented in the meta-modeling level. In this sense, this paper stands for a part of our ongoing work. Therefore, our preoccupations to be fulfilled in the near future lie mainly in (1) further validating the defined semantic consistency rules by referring to other independent modelers, (2) providing guidance for modelers to comply with these rules during the "process modeling" process and (3) enabling the synchronization between produced models (diagrams) when one of them undergoes a change in order to ensure a consistent state of the process models ecosystem.

\section{REFERENCES}

[1] S. Nurcan, J. Barrios, "Enterprise knowledge and information system modelling in an evolving environment", Proceedings of the first international workshop on Engineering Methods to Support Information Systems Evolution in conjunction with OOIS'03, Geneva, Switzerland, September 5, 2003.

[2] A. Persson, "The utility of participative enterprise modeling in information systems development-challenges and research issues", Proceedings of the 11th International Workshop on Database and Expert Systems Applications, IEEE, 2000.

[3] W. van der Aalst, V. ter Hofstede and M. Weske, "Business Process Management", Springer Lecture Notes in Computer Science 2678, Heidelberg, 2003.

[4] F. Daoudi, S. Nurcan, "A benchmarking framework for methods to design flexible business processes", Special issue of the Software Process: Improvement and Practice, Journal on "Business Process Management, Development and Support, vol.12, n.1, , JanuaryFebruary 2007.

[5] P. Loucopoulos, V. Kavakli, N. Prekas, C. Rolland, G. Grosz and S. Nurcan, "Using the EKD approach: the modelling component", 
ELECTRA Athena (projet ESPRIT IV), Centre de Recherche en Informatique, Paris 1 university, July 1997.

[6] P. Loucopoulos, V. Kavakli,'Enterprise knowledge management and conceptual modelling", In Conceptual Modeling, Springer, Berlin Heidelberg, 1999, pp. 123-143.

[7] V. Kavakli, P. Loucopoulos, "Goal-driven business process analysis application in electricity deregulation", Information Systems, vol. 24, n.3, pp. 187-207, 1999.

[8] D. Bork, D, E.J. Sinz,"Bridging the Gap from a Multi-View Modelling Method to the Design of a Multi-View Modelling Tool", Enterprise Modelling and Information Systems Architectures, vol. 8 , n.2, pp. 25-41, 2013.

[9] S. Nurcan, "Ingénierie et Architecture d'Entreprise et des Systèmes d'Information-Concepts, Fondements et Méthodes", Habilitation dissertation, Université Paris 1 Panthéon-Sorbonne, 2012.

[10] R. Kennett, "Implementing scrum using business process management and patterns analysis methodologies", Published at the Dynamic Relationships Management Journal, 2013.

[11] B. Benatallah, F. Casati, F. Curbera, F and W.M. van der Aalst, "Business Process Management", 3rd International Conference, BPM 2005, Nancy, France, September 5-8, 2005 ,

[12] B. Curtis, M.I. Kellner and J. Over, Over, J, "Process modeling". Communications of the ACM, vol. 35, n. 9 , pp. 75-90, 1992

[13] D. Bork, E.J. Sinz and D. Karagiannis, “A Development Method for the Conceptual Design of Multi-View Modeling Tools with an Emphasis on Consistency Requirements", Doctoral dissertation, Bamberg, Otto-Friedrich-Universität Bamberg, 2015.

[14] J. Krogstie, G. Sindre and H. Jørgensen, "Process models representing knowledge for action: a revised quality framework", European Journal of Information Systems, vol. 15, n.1, pp. 91-102, 2006.

[15] I. Vanderfeesten, H.A. Reijers, J. Mendling, W.M. van der Aalst and J. Cardoso, "On a quest for good process models: the crossconnectivity metric", In Advanced Information Systems Engineering. Springer Berlin Heidelberg, 2008, pp. 480-494.

[16] J.P. Van Belle, "A proposed framework for the analysis and evaluation of business models", In Proceedings of the 2004 annual research conference of the South African institute of computer scientists and information technologists on IT research in developing countries. South Africa, October 2004

[17] K. Ryndina, J.M. Küster and H. Gall, "Consistency of business process models and object life cycles", In Models in Software Engineering, Springer Berlin Heidelberg, 2006, pp. 80-90.

[18] G. Engels, J.M. Küster, R. Heckel, R and L. Groenewegen, "A methodology for specifying and analyzing consistency of objectoriented behavioral models". In ACM SIGSOFT Software Engineering Notes, vol. 26, no. 5, pp. 186-195, September 2001.

[19] R.E. Lopez-Herrejon, A. Egyed, "C2mv2: Consistency and composition for managing variability in multi-view systems", In 15th European Conference on Software Maintenance and Reengineering, March 2011.

[20] M.P. Papazoglou, W.J. van den Heuvel, "Configurable business objects for building evolving enterprise models and applications", In Business Process Management, Springer, Berlin, Heidelberg, 2000, pp. 328-344.

[21] J. Barrios and S. Nurcan,"Model driven architectures for enterprise information systems", In Advanced Information Systems Engineering, Springer, Berlin, Heidelberg, 2004, pp. 3-19.

[22] M. Persson, M. Törngren, A. Qamar, J. Westman, M. Biehl, S. Tripakis and J. Denil, J, "A characterization of integrated multiview modeling in the context of embedded and cyber-physical systems". In Proceedings of the Eleventh ACM International Conference on Embedded Software, September 2013.

[23] S. Nurcan, J. Barrios, G. Grosz, C. Rolland, "Change process modelling using the EKD-Change Management Method". In European Conference on Information Systems, 1999.

[24] S. Nurcan and C. Rolland, "Using EKD-CMM electronic guide book for managing change in organisations", In European-Japanese Conference on Information Modelling and Knowledge Bases, 1999.

[25] C. Rolland, P. Loucopoulos, V. Kavakli and S. Nurcan, "Intention based modelling of organisational change: an experience report". In proceedings of the fourth CAISE/IFIP 8.0 international workshop on
Evaluation of Modeling Methods in Systems Analysis and Design (EMMSAD'99), Heidelberg, Germany, June 14-15, 1999.

[26] D. Bork, R. Buchman and D. Karagiannis, "Preserving Multi-view Consistency in Diagrammatic Knowledge Representation". In Knowledge Science, Engineering and Management, Springer International Publishing, 2015, pp. 177-182.

[27] D. Bork, "Using conceptual modeling for designing multi-view modeling tools", Proceedings of the $21^{\text {st }}$ Americas conference on information systems (AMCIS), Puerto Rico, United States of America2015.

[28] A. Gunka, Seycek and H. Kühn, "Moving an application to the cloud: an evolutionary approach". In Proceedings of the international workshop on Multi-cloud applications and federated clouds, April 2013.

[29] H.G. Fill, "On the conceptualization of a modeling language for semantic model annotations", In Advanced Information Systems Engineering Workshops, Berlin Heidelberg, June 2011.

[30] D. Karagiannis, C. Moser and A. Mostashari, "Compliance evaluation featuring heat maps (CE-HM): a meta-modeling-based approach". In Advanced Information Systems Engineering, Springer, Berlin, Heidelberg, 2012, pp. 414-428.

[31] H.G. Fill, P. Loucopoulous and R.Woitsch,"Realization of conceptual modeling tools for value creation: A case study on EKDconcepts", 2014.

[32] S.I.D.D. Pádua, R.Y. Inamasu, "Assessment method of the business process model of EKD”. Gestão \& Produção, vol.15, n.3, pp. 563$578,2008$.

[33] A. Awadid, S. Nurcan, "A Systematic Literature Review of Consistency among Business Process Models", Proceedings of the $17^{\text {th }}$ edition of the Business Process Modeling, Development, and Support (BPMDS) series in conjunction with CAiSE'16, Ljubljana, Slovenia, June 13-14, 2016, in press. 